\title{
BMJ Global Health Barriers to decolonising educational partnerships in global health
}

\author{
John Kulesa (1) , ${ }^{1,2}$ Nana Afua Brantuo ${ }^{1,3}$
}

\begin{abstract}
To cite: Kulesa J, Brantuo NA. Barriers to decolonising educational partnerships in global health. BMJ Global Health 2021;6:e006964. doi:10.1136/ bmjgh-2021-006964
\end{abstract}

Handling editor Seye Abimbola

Received 21 July 2021

Accepted 1 November 2021

\section{Check for updates}

(c) Author(s) (or their employer(s)) 2021. Re-use permitted under CC BY-NC. No commercial re-use. See rights and permissions. Published by BMJ.

${ }^{1}$ Graduate School of Education and Human Development, George Washington University, Washington, DC, USA

${ }^{2}$ Department of Hospital Medicine, Children's National Hospital, Washington, DC, USA ${ }^{3}$ Department of Education, University of Maryland at College Park, College Park, Maryland, USA

Correspondence to

Dr John Kulesa;

kulesaj@gmail.com

\section{ABSTRACT}

Global health partnerships between high-income countries and low/middle-income countries can mirror colonial relationships. The growing call to advance global health equity therefore involves decolonising global health partnerships and outreach. Through decolonisation, local and international global health partners recognise nonwestern forms of knowledge and authority, acknowledge discrimination and disrupt colonial structures and legacies that influence access to healthcare.

Despite these well-described aims, the ideal implementation process for decolonising global health remains ill-defined. This ambiguity exists, in part, because partners face barriers to adopting a decolonised perspective. Such barriers include overemphasis on intercountry relationships, implicit hierarchies perpetuated by educational interventions and ethical dilemmas in global health work.

In this article, we explore the historical entanglement of education, health and colonialism. We then use this history as context to identify barriers that arise when decolonising contemporary educational global health partnerships Finally, we offer global health partners strategies to address these challenges.

\section{INTRODUCTION}

The energy of the anti-racism movement has brought many countries to a strategic historical juncture, inspiring them to reevaluate the effects of colonialism on the rights, well-being and cultural integrity of peoples in the Global South. ${ }^{1-5}$ As an extension of that process, there has been a surge of interest in decolonising global health partnerships. ${ }^{6-8}$

In educational global health partnerships, practitioners from high-income countries (HICs) work jointly with practitioners and community members from low/middleincome countries (LMICs) through bidirectional education. Together, partners engage community members and strengthen individual and institutional capacities to provide healthcare. Adopting a 'decolonised' perspective in these partnerships involves dismantling colonial educational structures, addressing western hegemony, and, for indigenous scholars such as Tamale, 'reclaiming
Summary box

Global health educational partnerships can perpetuate colonial legacies that limit access to healthcare and contribute to poor health outcomes.

- Barriers arise when decolonising global health; global health partners may struggle to ensure inclusion of all social and cultural groups affected by global health work, prevent the so-called 'nervous conditions' of inequality and resolve ethical dilemmas.

- Educators must include community stakeholders in targeted needs assessments, promote positive deviance and foster cultural safety.

- Global health practitioners from high-income countries should immerse themselves in the communities they serve to minimise power differentials.

- Foreign and local partners must communicate closely to determine an appropriate moral framework through which to view ethical dilemmas.

- Future education for global public health practitioners should directly target strategies to overcome these barriers.

our humanity; rebuilding our territorial and bodily integrity (and) reasserting our selfdetermination'. 910

Despite recent momentum, the optimal approach to decolonising educational global health partnerships remains ill-defined. Some scholars have called for the re-politicisation of global health (ie, grounding the field in a health justice framework and demanding increased diversity of educational leadership). ${ }^{11}$ Some argue that partners must re-centre indigenous knowledges, ontologies and epistemologies to reverse the overrepresentation of the Caucasian western male. ${ }^{7} 12$ Some educational leaders advocate for equal authorship, decentralised and democratised knowledge platforms, and complete removal of racism and hierarchy from global health institutions. ${ }^{13}$ Others ask global health practitioners to reject 'saviorism' by refusing to participate in partnerships that do not give equal opportunity and reward to partners from LMICs. ${ }^{14}$

Although these strategies contribute to a growing consensus on how to approach 
decolonisation, we argue that these recommendations do not provide sufficient guidance for those engaged in educational global health partnerships. Specifically, partners may face logistical and ethical challenges operationalising these recommendations. The primary aims of this article are to (1) highlight barriers that arise when implementing recommendations to decolonise educational global health partnerships, and (2) offer strategies to tackle those barriers.

In this piece, we briefly describe the historical entanglement of education, healthcare and colonialism to offer context; we use that history to highlight barriers that arise when decolonising educational global health partnerships and we offer suggestions for how to approach problem solving to overcome those barriers. Throughout this piece, we use illustrative examples from sub-Saharan Africa, a region heavily colonised by Europe in the early 1900s and a nidus for decolonisation efforts. ${ }^{15}$

\section{HISTORY OF COLONIALISM, EDUCATION AND HEALTHCARE}

During the colonial era, cooperation between colonial authorities and the church resulted in interfacing educational, political, religious and healing systems 'intimately tied to a repressive, coercive and violent system of power and knowledge'. ${ }^{16}$ Classroom education for indigenous pupils targeted skills that specifically prepared students for roles in factories, farms and mines to benefit European economic investments. Colonialists demonised indigenous education systems with false narratives about European spiritual, moral and intellectual superiority, cultivating the saviour mentality to justify, rationalise and legitimise their presence. ${ }^{17}$ Like religion and education, medicine served as a tool, or a biologic basis, to further divide and belittle indigenous populations. ${ }^{6}$ These tools intensified segregation in schools, increasing students' risk of internalising colonial stereotypes. ${ }^{18}$ Even more, costly higher education commodified knowledge, creating a social elite and limiting access to medical education. ${ }^{10}$ The social desirability of learning western biomedical practices led many to denounce traditional healing practices as barbaric and uncivilised. ${ }^{19}$

The very roots of global health, termed 'tropical medicine' during the colonial era, grew from racialised imagery of the 'diseased native' ${ }^{20}$ Colonialists predicted that, by protecting the local workforce through the 'conquest' of tropical diseases, they could improve economic productivity, trade and local living conditions. ${ }^{21}$ Tropical medicine evolved into international health which developed in tandem with the concept of global health governance, a system whereby HICs secured power to influence health in LMICs through private and public outreach. ${ }^{22}$ Through international health, foreign organisations shared western medical concepts with indigenous populations to address the perceived threat of disease transmission from LMICs to HICs.

As international health transitioned to modern-day global health, the concept of coloniality also evolved.
Richardson defined coloniality as, 'the matrix of power relations that persistently manifests transnationally and intersubjectively despite a former colony's achievement of nationhood'. ${ }^{23}$ Through coloniality, power relations between foreign and host-country stakeholders tacitly perpetuated internalised colonialism, or 'colonisation of the mind'. Internalised colonialism describes an attitude of ethnic or cultural inferiority experienced by individuals in previously colonised countries. ${ }^{1024}$ One indigenous scholar, Tamale, highlighted four processes that facilitate internalised colonialism, including: (1) othering: the act of creating categories which provide symbolic dimensions of a community but exclude those considered alien; (2) invisibilisation: the erasure or devaluation of non-western forms of knowledge; (3) binarisation: a reductionistic view of human relations which ignores multiplicity and fluidity (eg, categorising people as black or white, male or female, gay or straight) and (4) promotion of authoritative knowledges: allowing a system of knowledge to gain dominance over others within a group because group participants agree it 'counts in a particular situation'. 1025 Each of these processes intersects with education and influences the perception of whose knowledge matters and who is deserving of shared knowledge. Similarly, these processes promote prejudice against non-western forms of healing, limit access to healthcare for marginalised groups (eg, when stakeholders act on the belief that some individuals are not deserving of medical care) and contribute to poor health outcomes. ${ }^{26}$

\section{BARRIERS TO DECOLONISING PARTNERSHIPS}

Using this history as a lens to analyse modern-day global health partnerships, we identify several barriers that arise when implementing decolonisation principles.

\section{Overemphasis on intercountry relations}

Educational global health partnerships may involve a variety of stakeholders. For example, partners may include foreign global health practitioners, indigenous clinicians (eg, physicians, nurses, nutritionists, pharmacists) and local community members (eg, village chiefs, traditional healers, religious figures, community health workers). Diverse cultures (or cultural subgroups) can coexist in geographic regions affected by educational global health partnerships, and host-country stakeholders may have differing perspectives, values and cultures. The desire to represent and nurture local voices requires deliberate strategising and organising to ensure inclusion of all groups influenced by global health work. However, decolonisation efforts often target the relationship between foreign global health practitioner and indigenous clinician trained in western medicine. ${ }^{1427} 28$

This focus on decolonising intercountry relationships may be problematic. First, indigenous clinicians may not be able to understand or represent the perspectives and culture of all host-country stakeholders. This inability makes it challenging to adapt curricula to the needs 
of the local population and to anticipate the greater sociocultural effects of education. Second, focusing on intercountry relationships between foreign global health practitioners and local clinicians, who themselves practice western medicine, may only enhance western medical practice, prevalence and strength. The danger of supporting healthcare and health services education modelled on western biomedical practices is that these systems, even if adapted by local and international clinicians to meet the needs of the local population, may isolate cultural groups that are more distant from western culture. Because westernisation became a symbol of higher social status during the colonial era, cultural groups who continue to practice traditional medicine may be subjected to prejudice, othering and internalised colonialism perpetuated by global health work. When international non-governmental organisations and academic institutions offer resources to support indigenous clinicians who practice western biomedicine without also respecting and amplifying local healing practices, this may be a form of surrogate colonialism, or even co-optation.

Although the consequences of focusing on intercountry relationships seem clear, the reasons for this phenomenon remain unclear. Perhaps there is an overrepresentation of western voices guiding decolonisation efforts, and these western global health practitioners tend to focus on their own relationships. Alternatively, focusing on intra-country relationships may be logistically challenging due to resource constraints. Resources may include time, money and cultural and language expertise. As such, physical, financial and sociocultural access barriers may decrease communication between host-country partners. Lastly, not all stakeholders may value the principles of decolonisation. Disrupting colonial power structures may, in turn, disrupt existing sociocultural power imbalances, so those in power may not feel incentivised to dismantle coloniality.

As one example of this barrier, some international medical non-governmental organisations in Lesotho worked to decolonise their international relationships by hiring almost exclusively clinicians of the local Basotho culture. ${ }^{29}$ However, Basotho clinicians reported cultural tensions that affected their ability to educate patients and community members. For instance, women from rural villages wearing traditional face paint expressed discomfort and fear of rejection when seeking information and interacting with nurses. Clinicians also at times dismissed patients who reported symptoms using traditional terminology. As Moshabela described in nearby South Africa, even when local providers and patients shared the same cultural background, differences between cultural subgroups perpetuated othering and invisibilisation. ${ }^{30}$ To stress this point, Moshabela reported that, no matter how long western medical clinics had been established in South Africa, community members still viewed clinics as 'little colonies'. Without engaging diverse host-country partners, and with an overemphasis on intercountry relationships, partners struggled to successfully decolonise their relationships.

\section{Overcoming this barrier}

Decolonisation is a collective responsibility; the onus is on both stakeholders from HICs and LMICs. Therefore, decolonisation cannot be a segmented process, and collaboration involves communication and genuine shared decision making between all parties affected by educational partnerships. Partners must increase the complexity of their work to meet the complexity of their environment. ${ }^{31}$ To bring decolonisation rhetoric to practice, targeted needs assessments for any community and provider education need to involve diverse community stakeholders. As part of this process, partners can re-allocate resources to facilitate communication among stakeholders and budget for these resources early in the planning process. Also, partners may promote 'positive deviance', a process by which stakeholders discuss educational and healing practices that are already successful in the local context, rather than looking for best practices from other contexts. ${ }^{31}$ This process inherently keeps global health focused on community-level leadership and practice. Lastly, partners should cultivate cultural safety, a critical perspective defined by Mackean et al. Cultural safety encourages reflection, learning and listening, accountability and interface between diverse stakeholders. ${ }^{32}$ As part of promoting cultural safety, all partners should work to predict the greater impact of their work, recognise power imbalances and empower indigenous voices.

\section{'Nervous conditions' and implicit hierarchy}

Gilson describes that global health practitioners often think they must educate their host-country partners to 'fill the glass up', rather than nurturing and multiplying the knowledge, tradition, history, skills and competencies which already exist. ${ }^{30}$ We argue that knowledge sharing can itself create a hierarchy and implicitly devalue traditional customs when it is not paired with greater immersion into the local culture.

Many of the harms of colonisation relate to the "nervous conditions' created by western presence. Nervous conditions allude to the anxieties experienced by indigenous people as they grow increasingly conscious of social inequities and lose their sense of belonging in a society undergoing cultural change. ${ }^{33}$ For instance, colonialists who identified opportunities to change 'poor' living conditions in indigenous rural communities drove community members to seek a 'better life' by acquiring classroom education and assimilating into western culture. These individuals often encountered racism and rejection from European peers, as well as isolation from their own families. Those who adopted aspects of western culture experienced, as Lazarus describes, 'great expectations and the mourning after', referring to the feeling of nonacceptance. ${ }^{34}$ The pressure to westernise manifests in similar ways in today's society. Western partners often share 
western medical knowledge without also learning from or integrating into the cultures and societies they serve. When only host-country partners are willing to learn and adopt others' practices and culture, that dynamic creates an implicit hierarchy.

As an example, prior to the COVID-19 pandemic, educational global health partnerships enabled integration of western and African medicine (eg, adopting English as the language of health services education, using western technology to diagnose and treat medical conditions and so on). Many indigenous individuals also trained in western medicine and developed relationships with international aid organisations. However, during the first wave of the COVID-19 pandemic, international support dwindled in many countries, and some local partners experienced isolation. ${ }^{35}$ Many educational and medical aid organisations withdrew services and fired or furloughed personnel during this time. ${ }^{36}$ This withdrawal of aid, along with inequities in the distribution of vaccines and personal protective equipment, sent a message to hostcountry partners that US-based institutions may minimise host-country priorities. Even more, foreign institutions expressed that they were 'puzzled' by the fact that subSaharan Africa did not experience greater morbidity and mortality. ${ }^{37}$ As Fofana describes, this perception overlayed the greater expectation that sub-Saharan Africa was not equipped to succeed, a perception fueled by bias. Host-countries with long-standing relationships through educational global health partnerships faced new challenges independently during the COVID-19 pandemic, indicating an asymmetric power balance between HICs and LMICs and poor integration between indigenous and foreign partners. This asymmetry in the relationship counters the spirit of the decolonisation movement.

\section{Overcoming this barrier}

Practitioners must consider if community health educational interventions, regardless of how small, create nervous conditions and implicit hierarchies. We argue that, to remove those hierarchies, partners must immerse themselves in the communities they serve. This immersive experience involves recognising the power of cultural humility and continuing to serve communities in moments of crisis. ${ }^{30}$ To understand the impact of educational initiatives, and to create a sense of solidarity and equality, it takes time and effort to learn the community, its leaders, its practices and its language. ${ }^{38}$ This process should not be unidirectional, with host-country practitioners and community leaders assuming that burden. If global health practitioners cannot integrate into the local context, they should re-evaluate if their presence is warranted or beneficial.

\section{Ethical dilemmas in decolonisation}

One tenet of decolonisation theory involves treating traditional healing practices on equal footing with western medical practices so that they enrich each other. However, this principle may at times conflict with the desire to champion ethical and just behaviour. For example, partners may consider the following questions: How aggressively should partners encourage communities to abandon traditional practices that can potentially cause harm? What happens when educators meet resistance from community members that they cannot overcome with joint communication and perspective sharing? If public health practitioners choose not to create educational interventions to deter practices that can compromise patient safety, what are the ethical consequences?

As an example, research suggests that a subset of patients in Uganda developed hepatic fibrosis after exposure to traditional herbal remedies. ${ }^{39}$ Dosing regulation may have been protective. Another study from South Africa showed high rates of hospital utilisation from adverse drug reactions related to hepatotoxicity, often associated with concomitant use of antiretroviral therapies and traditional herbal remedies. ${ }^{40}$ In this instance, without educational interventions targeting traditional healers who prescribe these remedies, patients may suffer direct harm. If those patients then seek care at a hospital, their care may burden local health systems with high resource utilisation, affecting medical care for others with different cultural backgrounds and belief systems.

As another example, religious doctrine delivered through colonial education, per Viteri, introduced and reinforced heteronormativity, violence against women and queer youth, and the notion that some people are not deserving of medical care or shared knowledge. ${ }^{26}$ Momentum from international movements may legitimise and increase visibility of human rights campaigns which influence access to information and access to medical care. Foreign influence may therefore increase recognition and eventual reversal of colonial legacies. However, partners must consider if these foreign influences are also colonial in nature. Historically, interventions with benevolent intent have caused unforeseen harms (eg, short-term medical trips which use resources disproportionate to the benefits received by the host country; Human rights campaigns that create a savage-victim-saviour triad which vilifies indigenous peoples who act based on a culture that does not promote 'human dignity' by western standards). ${ }^{41}$ The risk of introducing additional harm through advocacy work should remain an ethical consideration for partners.

\section{Overcoming this barrier}

Decoloniality within global health policy, praxis and education must contend with and reconcile potential conflicts between decolonisation, the ethical principle of nonmaleficence and utilitarian ethical principles. In other words, it may be necessary to evaluate whether the potential social harms of advocating against traditional practices outweigh the direct medical harms to individuals and the risk of increased 
strain on healthcare systems. We argue that, at times, offering education and advocating against traditional practices may be necessary to protect patients' physical well-being.

Additionally, it will be challenging and necessary to anticipate and effectively manage the downstream effects of external influence on human rights campaigns in partner countries. Global health partners can and should, as the Global Social Work Statement of Ethical Principles states, 'interrogat[e] the principle of 'respect for diversities' (and caution) against a shift towards moral relativism, where culture is used as a disguise for human rights violations'. ${ }^{42}$ Such violations of human rights may include 'honour killing' and 'corrective rape'. Foreign and local partners must communicate closely to determine an appropriate moral framework through which to view ethical dilemmas.

\section{CONCLUSION}

We present several barriers to decolonising educational global health partnerships. Because of cultural heterogeneity within regions affected by educational global health partnerships, overemphasis on intercountry relationships stifles decolonisation efforts and decreases inclusivity and representation. Nervous conditions created from western influence may preserve colonisation of the mind and generate implicit hierarchies. Non-maleficence and utilitarian ethical principles may also challenge decolonisation efforts.

Global health partners must appropriately allocate resources to increase the complexity of their networks and match the complexity of their environment. Global health practitioners should recognise the value of immersion in the local culture to minimise the risk of creating hierarchy in global health work. Lastly, partners must jointly consider how they will evaluate and respond to ethical dilemmas. We argue global health partners cannot realise decolonisation without critically analysing these barriers and guiding global health students through the process of analysing and reflecting on these barriers within global health curricula.

\section{Acknowledgements The authors would like to thank Dr. Kathy Ferrer and Mr.} Hudson Munoz for their review of the manuscript

Contributors JK and NB conceptualised and drafted the manuscript.

Funding The authors have not declared a specific grant for this research from any funding agency in the public, commercial or not-for-profit sectors.

Competing interests None declared.

\section{Patient consent for publication Not applicable.}

Provenance and peer review Not commissioned; externally peer reviewed. Data availability statement There are no data in this work.

Open access This is an open access article distributed in accordance with the Creative Commons Attribution Non Commercial (CC BY-NC 4.0) license, which permits others to distribute, remix, adapt, build upon this work non-commercially, and license their derivative works on different terms, provided the original work is properly cited, appropriate credit is given, any changes made indicated, and the use is non-commercial. See: http://creativecommons.org/licenses/by-nc/4.0/.

\section{ORCID iD}

John Kulesa http://orcid.org/0000-0003-4031-4154

\section{REFERENCES}

1 Ndlovu-GatsheniSJ. Epistemic freedom in Africa: deprovincialization and decolonization. Routledge, 2018.

2 JacksonRH. The weight of ideas in decolonization: normative change in international relations. In: Ideas and foreign policy. Cornell University Press, 2019: 111-38.

3 DupuisAL. Decolonization and political engagement for the health and wellbeing of the Selish, Ksanka and Qlispe people 2017.

4 Burke R. Decolonization, Self-determination, and the rise of global human rights politics. Cambridge University Press, 2020.

5 Burke R. Decolonization and the evolution of international human rights. University of Pennsylvania Press, 2011.

6 Eichbaum QG, Adams LV, Evert J, et al. Decolonizing global health education: rethinking institutional partnerships and approaches. Academic Medicine 2021;96:329-35.

7 Affun-Adegbulu C, Adegbulu O. Decolonising global (public) health: from Western universalism to global pluriversalities. BMJ Glob Health 2020;5:e002947.

8 Lokugamage AU, Ahillan T, Pathberiya SDC. Decolonising ideas of healing in medical education. J Med Ethics 2020;46:265-72.

9 Fayemi AK, Macaulay-Adeyelure OC. Decolonizing bioethics in Africa. BEOnline 2016;3:68-90.

10 TamaleS. Decolonization and afro-feminism. Daraja Press, 2020.

11 Büyüm AM, Kenney C, Koris A, et al. Decolonising global health: if not now, when? BMJ Glob Health 2020;5:e003394.

12 Farag N. Why it's important for future healthcare professionals to understand'decolonizing'global health, and how this can be done. Available: http://www.perspectivesmcgill.com/opinion/2020/ 12/9/why-its-important-for-future-healthcare-professionals-tounderstand-decolonizing-global-health-and-how-this-can-be-done

13 Abimbola S, Pai M. Will global health survive its decolonisation? Lancet 2020;396:1627-8.

14 Oti SO, Ncayiyana J. Decolonising global health: where are the southern voices? BMJ Glob Health 2021;6:e006576.

15 Slavery and the "Scramble for Africa". BBC - History - British History in depth. Available: http://www.bbc.co.uk/history/british/abolition/ scramble_for_africa_article_01.shtml [Accessed $26 \mathrm{Mar}$ 2021].

16 Prince RJ, Marsland R. Making and unmaking public health in Africa: ethnographic and historical perspectives. Ohio University Press, 2013.

17 Shizha E, Kariwo MT. Impact of colonialism on education. In: Education and development in Zimbabwe. Brill Sense, 2011: 13-26.

18 Mfum-Mensah O. We come as members of the superior race: distortions and education policy discourse in sub-Saharan Africa. Berghahn Books, 2020.

19 Ikuenobe PA. Traditional African environmental ethics and colonial legacy. Int J Philos Theol 2014;2:1-21.

20 Farmer P, Kim JY, Kleinman A. Reimagining global health: an introduction. Vol. 26. Univ of California Press, 2013.

21 Packard RM. Malaria dreams: postwar visions of health and development in the third World. Med Anthropol 1997;17:279-96.

22 Levich J. The gates foundation, Ebola, and global health imperialism. Am J Econ Sociol 2015;74:704-42.

23 Richardson ET. On the coloniality of global public health. Medicine Anthropology Theory 2019;6.

24 Wa Thiong'o N. Decolonising the mind: the politics of language in African literature. East African Publishers, 1992.

25 Low LK, Tumbarello JA. Falling out: authoritative knowledge and women's experiences with pelvic organ prolapse. J Midwifery Womens Health 2012;57:489-94.

26 Viteri M-A. Desbordes: translating racial, ethnic, sexual, and gender identities across the Americas. SUNY Press, 2014.

27 Holst J. Global health - emergence, hegemonic trends and biomedical reductionism. Global Health 2020;16:42.

28 Plamondon KM, Brisbois B, Dubent L, et al. Assessing how global health partnerships function: an equity-informed critical interpretive synthesis. Global Health 2021;17.

29 Kulesa J, Chua I, Crawford L, et al. Cultural considerations in health care capacity building: a qualitative study in Lesotho. Glob Public Health 2021:1-14.

30 Gilson L, Moshabela M. Global health, development, and colonialism. Decolonizing global health Georgetown seminar series, 2020. Available: https://www.youtube.com/watch?v=m2ZepKwOjsg 
31 Snowden DJ, Boone ME. A leader's framework for decision making. A leader's framework for decision making. Harv Bus Rev 2007;85:68.

32 Mackean T, Fisher M, Friel S, et al. A framework to assess cultural safety in Australian public policy. Health Promot Int 2020;35:340-51.

33 Dangarembga T. Nervous conditions. Faber, 2020.

34 Lazarus N. Great expectations and the mourning after: decolonization and African intellectuals. In: Resistance in postcolonial African fiction new Haven. Yale UP, 1990.

35 Acharya KP, Ghimire TR, Subramanya SH. Access to and equitable distribution of COVID-19 vaccine in low-income countries. NPJ Vaccines 2021;6:1-3.

36 Analytica O. COVID-19 complicates global humanitarian aid response. Emerald Expert Briefings, 2020.

37 Fofana MO. Decolonising global health in the time of COVID-19. Glob Public Health 2021;16:1155-66.
38 Perumal JC. Critical pedagogies of place: educators' personal and professional experiences of social (in)justice. Teaching and Teacher Education 2015;45:25-32.

39 Auerbach BJ, Reynolds SJ, Lamorde M, et al. Traditional herbal medicine use associated with liver fibrosis in rural Rakai, Uganda. PLoS One 2012;7:e41737.

40 Mouton JP, Njuguna C, Kramer N, et al. Adverse drug reactions causing admission to medical wards: a cross-sectional survey at 4 hospitals in South Africa. Medicine 2016;95:e3437.

41 Savages, victims, and saviors: the metaphor of human rights. Harv Int'l LJ 2001;42:201 https://digitalcommons.law.buffalo.edu/journal_ articles/570/

42 Sewpaul V, Henrickson M. The (r)evolution and decolonization of social work ethics: the global social work statement of ethical principles. Int Soc Work 2019;62:1469-81. 